\title{
UPTAKE AND TRANSFER OF HIGH PCB CONCENTRATIONS FROM PHYTOPLANKTON TO AQUATIC BIOTA
}

\author{
Juei Shen Wang ${ }^{1 *}$, Hong Nong Chou ${ }^{2}$, Jin-Jia Fan, and Chien-Min $\mathrm{Chen}^{3}$ \\ ' Department of Food Health, Chia Nan College of Pharmacy and Science, Tainan 71710, Taiwan. \\ ${ }^{2}$ Institute of Fisheries Science, National Taiwan University, Taipei, Taiwan. \\ ${ }^{3}$ Department of Environmental Engineering and Health, Chia Nan College of Pharmacy and Science, \\ Tainan 71710, Taiwan
}

(Received in Germany 18 July 1997; accepted 15 August 1997)

\begin{abstract}
The uptake and transfer of $2,2^{\prime}, 4,4^{\prime}$-tetrachlorobiphenyl (an isomer of polychlorinated biphenyls, PCBs) in the culture of two species of phytoplankton, Nannochloropsis oculata and Isochrysis galbana, to brine shrimp (Artemia sp.) nauplii and hard shell clam (Meretrix lusoria) were investigated in a short-term laboratory ecosystem. Three PCB concentrations, $0 \mathrm{ppb}, 50 \mathrm{ppb}$ and $500 \mathrm{ppb}$, were prepared in the algal culture for examing the levels of PCB bioaccumulation and growth effects on these biota. Artemia and hard shell clam each when exposed to $500 \mathrm{ppb}$ contaminated Nannochloropsis and Isochrysis for $4 \mathrm{~d}$ could significantly bioaccumulate PCB concentrations up to $318.81 \mathrm{ppm}$ and $22.55 \mathrm{ppm}$ (dry basis), respectively. This may account for the high PCB residues that bioaccumulated in contaminated Nannochloropsis (257.52 ppm) and Isochrysis $(64.22 \mathrm{ppm})$ through the aquatic food chain. Biomass of PCB treated algae were apparently depressed $(p<0.05)$ relative to that of the control group $(0 \mathrm{ppb})$. Growth conditions (length and larva/mL) of Artemia when fed with Nannochloropsis under PCB environments also showed stronger inhibition effects compared to that of the control group $(p<0.05)$. 01998 Elsevier Science Ltd
\end{abstract}

Keywords: Polychlorinated biphenyls, uptake, phytoplankton, Artemia, hard shell clam.

\section{INTRODUCTION}

Polychlorinated biphenyls (PCBs) are very stable organic chlorinated compounds and have been extensively used in industry because of their wide range of physical properties and their chemical stability. According to estimates, more than $30 \%$ of the 120 million tons of PCB produced since 1929 have been released into the open environment (Tanabe 1988). This persistent pollutant eventually finds its way to the water column and results in toxicological effects on the aquatic ecosystem of a wide variety of species ranging from phytoplankton to marine mammals (Spacie and Hamelink 1985; Phillips 1994). Due to their hydrophobicity and low degradability, PCB could be accumulated as high as thousands- or tens thousand-time concentrations in biota relative to the concentrations present in the aquatic environment (Van der Oost et al.1988; Oliver and Niimi 1988). Their

\footnotetext{
* To whom correspondence should be addressed.
} 
toxicity to aquatic biota is further enhanced by their ability to bioaccumulate and biomagnify within the food chain due to extremely high liposolubility (Clark and Mackay 1991; van Sprang et al. 1991). Serving as a valuable food sources for the higher trophic level, phytoplankton plays a very important role in supporting the growth of many aquatic biota. Once in the water column, the lipophilic PCBs partition into the more nonpolar compartments of the aquatic ecosystem or are physically absorbed in particulate matters. Results indicate that the PCBs uptake process on microparticulate materials and into phytoplankton is consistent with partitioning from water into cell lipids (Rohrer et al. 1982; Swackhamer and Skoglund 1993). However, the occurrence of organochlorine residues in aquatic organisms of the food chain usually starts with the first link of the marine phytoplankton. The importance of this process is that it may cause a biomaginfication of the hydrophobic organic compounds to other higher trophic levels of aquatic biota. Various studies have also reported that most of the contaminants in aquatic biota are accumulated by dietary consumption through the food web rather than by direct uptake from water (Evans et al. 1982; Thomann and Connolly 1984; Van der Oost et al. 1988). By using the food-chain model, up to $99 \%$ of the PCBs is accumulated through dietary consumption rather than uptake from water (Rasmussen et al. 1990). Thus, information for the uptake of chlorinated contaminants in phytoplankton and the transfer to higher levels of aquatic biota in the food chain system is needed and should not be ignored.

Previous studies have shown that increased PCB levels in the water column increase the potential for PCB uptake in all trophic levels of the ecosystem (Brown et al. 1982; Califano et al. 1982; O'Connor and Pizza 1987). Although, most reports of PCB uptake by aquatic biota have been determined or monitored based on ambient concentrations in a natural environment, information of relative high concentrations on the resulting transfer and uptake has been scarce. In the present study, two common microalgae species found in local aquaculture, Nannochloropsis oculata and Isochrysis galbana, were therefore used in this short-term ecosystem to measure the uptake and transfer of PCBs to other trophic levels of aquatic biota, brine shrimp (Artemia sp.) and hard shell clam (Meretrix lusoria). Growth effects of these aquatic biota were also measured under the culture with high PCB concentrations.

\section{MATERIALS AND METHODS}

A purity $>99.0 \%$ of 2,2',4,4'-tetrachlorobiphenyl (an isomer of PCBs, purchased from Ultra Scientific, USA) was weighed and dissolved in a series of dilution with acetone to achieve $100 \mathrm{ppb}$ as standard stock in the present study. A salinity of $15 \%$ Esdschreiber medium was prepared as shown in Table 1 by filtration of $30 \%$ clean seawater through a $0.22 \mu \mathrm{m}$ microfilter with the addition of the same volume of deionized water. The prepared artificial medium was then sterilized at $121^{\circ} \mathrm{C}$ for $20 \mathrm{~min}$ and cooled to room temperature for the culture of microalgaes. Two pure culture of microalgaes, Nannochloropsis. oculata and Isochrysis galbana were provided by the Institute of Fisheries Science, National Taiwan University. Artemia nauplii were obtained by hatching the cysts (Artemia salina, San Francisco Bay Brand) in filtered seawater (30\%o salinity) under strong aeration for 20 hr. Hard shell clam (Meretrix lusoria) with an average diameter $2.5 \mathrm{~cm}$ were sampled at a local aquaculture farm. 
analysis. A gas chromatography (Perkin-Elmer Auto System GC) equipped with an ${ }^{63} \mathrm{Ni}$ electron capture detector and a programming integrator (PE Nelson Integrator) were used for the determination of PCB. The fused silica capillary column was a DB-608, $30 \mathrm{~m} \times 0.32 \mathrm{~mm}$ I.D., $0.5 \mu \mathrm{m}$ film thickness (J\&W Scientific, USA). The operating temperatures for the injector, column and detector were kept at $280^{\circ} \mathrm{C}, 220^{\circ} \mathrm{C}$ and $380^{\circ} \mathrm{C}$, respectively. High purity nitrogen was used as the carrier gas and make-up gas with flow rates, $29.0 \mathrm{ccc} . / \mathrm{min}$ and $35.5 \mathrm{~mL} / \mathrm{min}$, respectively. One $\mu \mathrm{L}$ each of sample and PCB standard was injected into $\mathrm{GC}$ at a splitless injection mode. Quantification of the concentrations was calculated by comparison of peak areas and standard injection. The recovery of PCB after extraction and clean-up procedures was $80-90 \%$. The detection limit of each compound was $1.0 \mathrm{ppb}$ (dry wt basis) in this study.

\section{RESULTS AND DISCUSSION}

Upon incorporation into phytoplankton, PCBs have been documented to exert inhibitory effects on photosynthesis and cell motility with direct toxic effects on algae and are readily bioaccumulated into the aquatic food chain (O'Connors et al. 1978; Rohrer et al. 1982; Evans et al. 1991). An as low as 0.1 ppb concentration of Aroclor 1254 (with $54 \%$ chlorine of PCBs) has shown to produce growth reductions in marine diatoms and a freshwater algae (Scenedesmus quadricauda) and altered the population structure of phytoplankton communities (EPA 1980). Among these sublethal effects, disruption of internal chloroplast membranes and failure of cytokinesis were reported as the major changes observed (Mahanty et al. 1983). Furthermore, marine algae exhibited greater-than-expected reductions in photosynthesis when stressed with mixtures of PCBs and DDE (Ernst 1984).

Figure 1 shows the relative biomass percentages (relative to the biomass at day 0 ) when Nannochloropsis and Isochrysis were contaminated under three different PCB concentrations $(0 \mathrm{ppb}, 50 \mathrm{ppb}$ and $500 \mathrm{ppb})$ with Artemia nauplii and hard shell clam for $4 \mathrm{~d}$, respectively. After feeding to Artemia nauplii, Nannochloropsis of all groups showed a decrease of algae biomass within $3 \mathrm{~d}$, whereas all groups ofNannochloropsis had an apparent increase of biomass after day 3 . In the Nannochloropsis culture with the Artemia predator, the relative biomass of control group were significantly higher than the other two PCB groups $(p<0.05)$ at each day. The relative biomass for $50 \mathrm{ppb}$ and $500 \mathrm{ppb}$ PCB treated group were very similar during the whole experiment. However, the increasing biomass for the two contaminated groups after day 3 showed that the algae species was not inhibited up to $500 \mathrm{ppb}$ PCB concentration. According to the study by Fisher et al. (1973), the diatoms Thalassiosira psewdonana and Skeletonema costatum were depressed in growth between 10-25 ppb of PCBs in water, while Dunaliella tertiolecta (a green algae) could support concentrations as high as $1000 \mathrm{ppb}$. Similar response from those phytoplankton species also indicated that over 118-h culture periods the cell densities of the treated cultures relative to control cultures for Bellerochia, Fragilaria pinnata and Thalassiosira pseudonana can decrease to $0.5 \%, 39 \%$ and $34 \%$, respectively. Algal strains, Thalassiosira nordenskioldii and Asterionclla glacialis, resistant to more than $50 \mathrm{ppb}$ of PCBs have been isolated from a highly polluted estuary and shown to enhance their growth in PCB contaminated water (Duncan 1983; Snyder 1985; Cosper et al. 1988). In the 


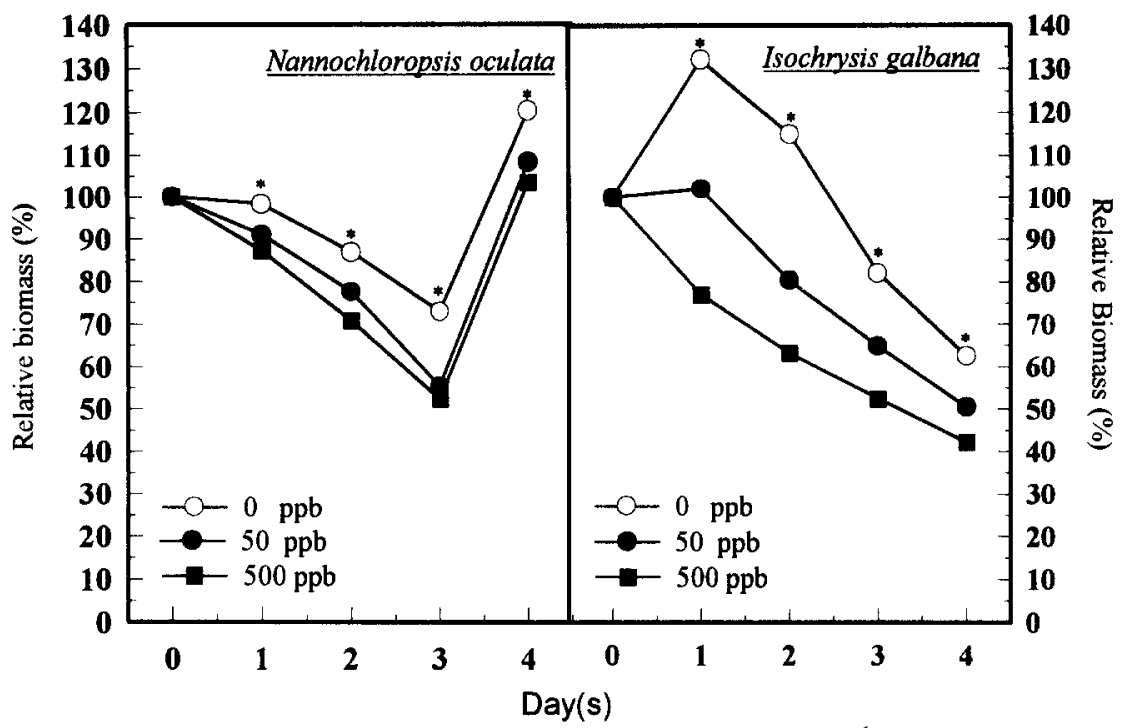

Fig. 1. Relative biomass of Nannochloropsis oculata (relative to $3.56 \times 10^{6} \mathrm{cell} / \mathrm{mL}$ at day 0 ) and Isochrysis galbana (relative to $1.13 \times 10^{6} \mathrm{cell} / \mathrm{mL}$ at day 0 ) in the culture with Artemia and hard shell clam, respectively, under three different PCB concentrations $(0,50$ and $500 \mathrm{ppb})$ for $4 \mathrm{~d}$. Significant differences between control group and each PCB contaminated group in the same day are indicated by ${ }^{*}(p<0.05)$.

present study, the capability for Nannochloropsis to tolerate higher than $500 \mathrm{ppb}$ of PCB and maintain its growth is possible.

For the Isochrysis culture, both $0 \mathrm{ppb}$ and $50 \mathrm{ppb}$ PCB groups had an increase of relative biomass (133\% and $102 \%$, respectively) compared to that of $500 \mathrm{ppb}$ group (77\%) at 1-d experiment (Fig. 1). The result confirms that up to $500 \mathrm{ppb}$ of PCB may be sensitive to Isochrysis and cause a growth inhibition in $24 \mathrm{~h}$. A decreasing relative biomass at $2 \mathrm{~d}(115 \%), 3 \mathrm{~d}(84 \%)$ and $4 \mathrm{~d}(62 \%)$ for the control group demonstrated that hard shell clam became accustomed to the culture and started consuming the Isochrysis species. The significantly lower biomass $(p<0.05)$ on both PCB contaminated groups than control group on each day also demonstrate that both $50 \mathrm{ppb}$ and $500 \mathrm{ppb}$ concentrations result in growth inhibition on Isochrysis. However, no mortality was found for any hard shell clam (Meretrix lusoria) tested in the present ecosystem under the Isochrysis culture with three different PCB concentrations. This indicates that this bivalve may tolerate as high as $500 \mathrm{ppb}$ PCB under the static food chain environment for $4 \mathrm{~d}$.

The growth effect on the length of Artemia nauplii during the 4-d period under different PCB conditions in Nannochloropsis culture is shown on Figure 2. The control group of Artemia had an significant increase of length on the 4-d experiment compared to the other two PCB groups $(p<0.05)$. The highest average length increases were found in the control group, from $751 \mu \mathrm{m}$ at $1-\mathrm{d}$ to $960 \mu \mathrm{m}$ at $4-\mathrm{d}$ compared to other two 


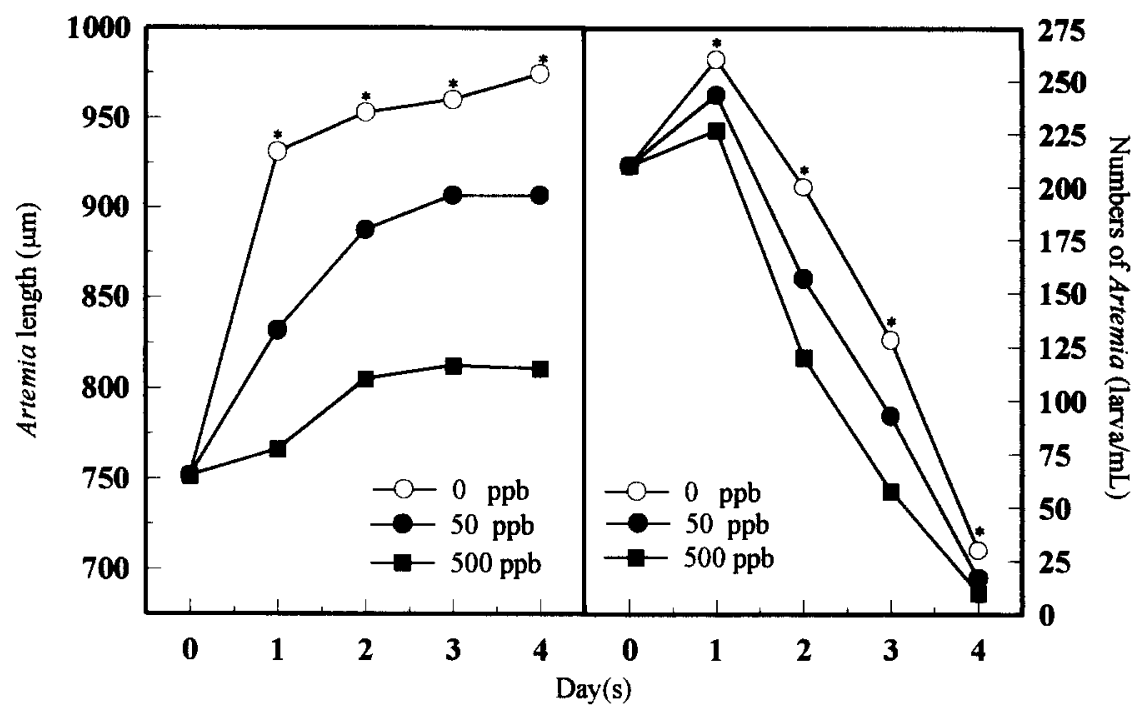

Fig. 2. Average Artemia length ( $\mu \mathrm{m})$ and numbers of nauplii $(\mathrm{larva} / \mathrm{mL})$ in the culture of Nannochloropsis oculata under three different PCB concentrations $(0,50$ and $500 \mathrm{ppb}$ ) for $4 \mathrm{~d}$. Significant differences on control group and each PCB contaminanted group in the same day are indicated by $*(p<0.05)$.

contaminated groups at each day. The 500 ppb PCB group caused the lowest average length increases, from 751 $\mu \mathrm{m}$ at 1-d to $810 \mu \mathrm{m}$ at 4-d. An elevated level of PCB concentration seems consistent with the growth inhibition on Artemia for the first 4-d period. The steady length increases for both PCB groups after $3 \mathrm{~d}$ suggest that the two PCB treated cultures apparently exhibited growth reduction on Artemia compared to the control group. For the survival conditions of the nauplii as shown in Figure 2, we found that the control group caused the higher number of Artemia compared with the other two PCB groups on each day $(p<0.05)$. As a lower number of zooplankton found in an enclosed aquatic environment, a higher biomass of the algae could be observed under normal conditions. The lowest number of Artemia nauplii together with the lowest relative biomass of Nannochloropsis was found under the 500 ppb PCB environment over the 4-d period (Fig. 1 and 2). Hence, we can conclude that $500 \mathrm{ppb}$ PCB could cause apparent growth reduction and toxic effects on Artemia by feeding with contaminated Nannochloropsis compared with the other two groups.

Levels of PCB bioaccumulation analyzed for Nannochloropsis and Artemia under three different PCB concentrations in the culture are shown in Figure 3. In the present study, PCB concentration of Nannochloropsis after 4-d inoculation on $500 \mathrm{ppb}$ PCB culture (257.52 ppm) was about 5.5-time than that of $50 \mathrm{ppb}$ PCB culture (46.51 ppm). As the number of algal cells increased in the culture, PCB were partitioned onto the cells and resulted in an increase in the total amount of PCB in the biomass. After 4-d food chain ecosystem, levels of PCB for the Artemia in $0 \mathrm{ppb}, 50 \mathrm{ppb}$ and $500 \mathrm{ppb}$ groups were $0.83 \mathrm{ppm}, 27.02 \mathrm{ppm}$ and $318.81 \mathrm{ppm}$ (in dry basis), 


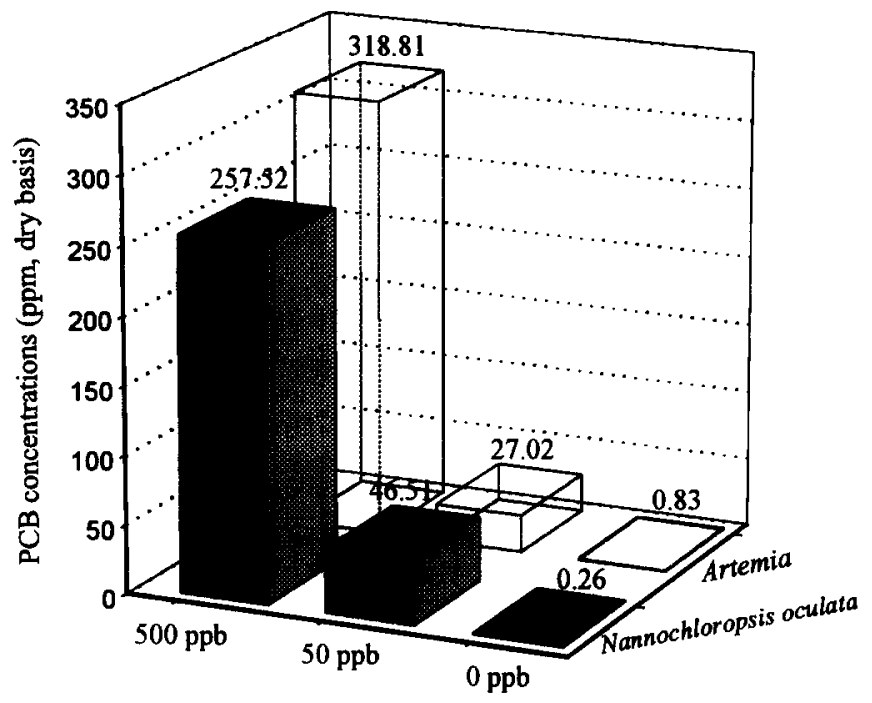

Fig 3. Levels of PCBs (ppm, dry basis) in Nannochloropsis oculata and Artemia after 4-d culture under three different PCB concentrations $(0,50$ and $500 \mathrm{ppb})$

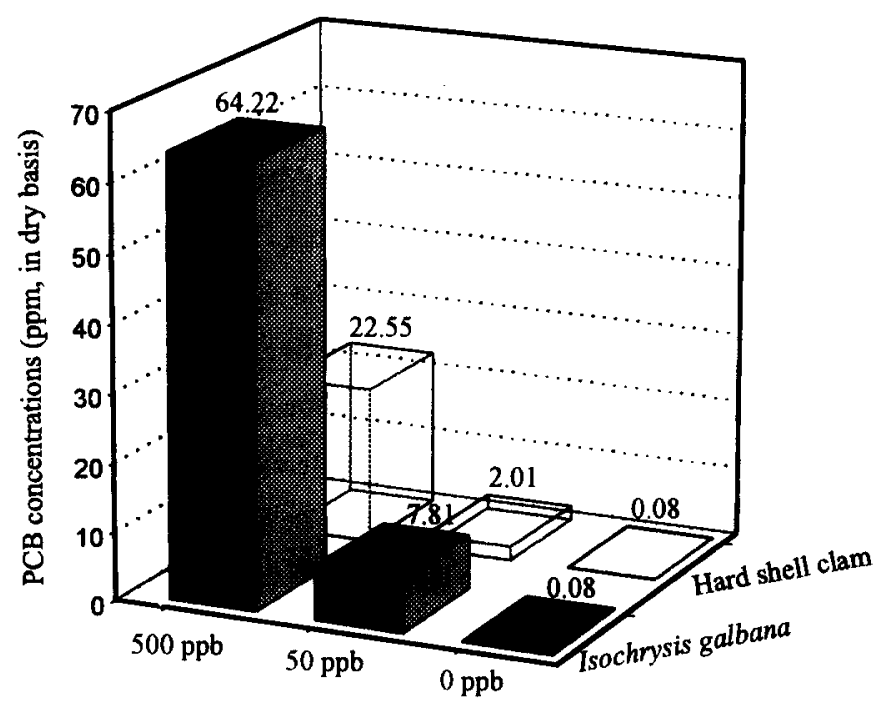

Fig 4. Levels of PCBs (ppm, dry basis) in Isochrysis galbans and hard shell clam after 4-d culture under three different PCB concentrations $(0,50$ and $500 \mathrm{ppb})$. 
respectively. The value of PCB bioaccumulation on $500 \mathrm{ppb}$ group is 11.8-time than that of $50 \mathrm{ppb}$ group, which is about the ratio of two prepared PCB concentrations on two aqueous solutions. This finding supports the conclusion of Scura and Theilacker (1977) indicating that PCB are concentrated up in each trophic level of a marine food chain consisting of the algal flagellate Dunaliella sp., the rotifer Brachionus plicatilis, and the larva of the northern anchovy Engraulis mordax. The data in that study also suggested that final concentration for the aquatic biota appeared to be dependent on the PCB concentration in the seawater and appeared to be an amplification in a step-wise fashion up the food chain.

The concentrations of PCB bioaccumulated in the other two trophic levels of the aquatic food chain are presented in Figure 4. Hard shell clam and Isochrysis on two PCB concentration groups bioaccumulated significantly high amounts of the pollutant compared to that of the control group. Uptake of PCB by the Isochrysis after $4 \mathrm{~d}$ for the $500 \mathrm{ppb}$ group averaged $64.22 \mathrm{ppm}$ (dry basis) which is about 8.2 times greater than that of the $50 \mathrm{ppb}$ group (7.81 ppm). The levels of PCB in hard shell clam after $4 \mathrm{~d}$ for the $500 \mathrm{ppb}$ and $50 \mathrm{ppb}$ groups through the food chain system were determined to be $22.55 \mathrm{ppm}$ and $2.01 \mathrm{ppm}$ (dry basis), respectively. The level of PCB bioaccumulated on hard shell clam from $500 \mathrm{ppb}$ group in the present study was about 11.2 times greater than that of the $50 \mathrm{ppb}$ group.

According to Scura and Theilacker (1977), there appears to be a biological magnification of PCB up the food chain based on a dry weight basis, suggesting that higher members of the food chain may accumulate PCB by eating members of lower trophic levels. Duursma and Marchand (1974) also reported that the PCB whole body concentration increased to $425 \mathrm{ppm}$ for oysters (Crassostrea virginica) held in sea water with $5 \mathrm{ppb}$ PCB and to $100 \mathrm{ppm}$ in sea water with $1 \mathrm{ppb}$ PCB. In the present study, the uptake levels on $500 \mathrm{ppb}$ PCB group for Artemia and hard shell clam were both found to be about 11 times than that on $50 \mathrm{ppb}$. However, only 5.9-time and 4-time difference of bioamplifiction between $500 \mathrm{ppb}$ and $50 \mathrm{ppb}$ PCB groups were found on each of Nannochloropsis and Isochrysis culture, respectively. This can be explained by the different partition coefficients of PCB on different biological properties of algal species. According to various reports, different levels of accumulation in the aquatic biota are closely associated to different species or biomass of biota, length of time and contamination conditions (Clayton et al. 1977; Scura and Theilacker 1977; Borgmann et al. 1990). Another reason for the low levels of PCB bioamplification in algae may be that a partition equilibrium between PCB in the aqueous and the phytoplankton has not yet reached.

A more clear correlation of the extent of PCBs uptake by these two phytoplankton species is expressed as the values of bioconcentration factor (BCF) in Table 2. In the present study, the log BCF values from $50 \mathrm{ppb}$ (2.97) and $500 \mathrm{ppb}$ (2.71) in Nannochloropsis group are higher than each of PCB treatment at Isochrysis group. The static system in this study may cause lower BCF values than the reports by Ernst (1984) who indicated that species of algae could concentrate PCBs over water levels by 10,000. According to Skoglund et al. (1996), the PCB uptake by algae is extensive and rapid and remains constant for approximately 24-48 h due to surface 
Table 2. The values of log bioconcentration factor (BCF) for two phytoplankton species under two PCB contaminated concentrations (50 and $500 \mathrm{ppb}$ ) after 4-d culture

\begin{tabular}{lcc}
\hline PCB concentrations & \multicolumn{2}{c}{$\underline{\log B C F}^{*}$} \\
\hline $50 \mathrm{ppb}$ & 2.97 & 2.19 \\
$500 \mathrm{ppb}$ & 2.71 & 2.11 \\
\hline
\end{tabular}

${ }^{*} \log \mathrm{BCF}=\log \frac{\text { PCBs }(\mathrm{ppm}, \mathrm{dry} \text { basis) in phytoplankton }}{\mathrm{PCBs}(\mathrm{ppm}) \text { prepared in culture }}$

adsoption. Increased biomass may also result in proportionately more rapid PCBs uptake and moderate increases in the total amount of uptake (Richer and Peters 1993). This is correlated to the increased Nannochloropsis biomass at day 4 that caused higher $\log$ BCF than that of Isochrysis which had lower biomass at day 4 . In the present study the higher PCB concentration that caused the higher mortality on phytoplankton may also result in lower BCF values on the biomass.

The present study reveals that the mechanism of the food chain phenomenon is a significant route for the uptake of high PCB concentrations from lower trophic biota - phytoplankton - to other aquatic predators. Moreover, the significant PCB transfer to other aquatic biota may also depend on different pollutant concentrations.

\section{ACKNOWLEDGMENTS}

The research was supported by the National Science Council of Taiwan (Grant No. NSC 83-0115-C-002-0022) and Chia Nan College of Pharmacy and Science at Tainan, Taiwan. The authors are also grateful for valuable comments on this manuscript provided by Dr. Min-Nan Lin from the Tainan Branch of the Taiwan Fisheries Research Institute

\section{REFERENCES}

Bastian, M. V. and D. W. Toetz. 1982. Effect of eight polynuclear hydrocarbons on growth of Anabaena flosaqueae. Bull. Environ. Contam. Toxicol. 32: 597-601.

Borgmann, U., W. P. Norwood and K. M. Ralph. 1990. Chronic toxicity and bioaccumulation of 2,5,2',5'- and $3,4,3^{\prime}, 4^{\prime}$ - tetrachlorobiphenyl and Aroclor 1242 in the Amphipod Hylella azteca. Arch. Environ. Contam. Toxicol. 19:558-564.

Brown, M. P., J. J. am McLaughlin, J. M. O'Connor and K. Wyman. 1982. A mathematical model of PCB bioaccumulation in plankton. Ecol. Model. 15: 29-47.

Califano, R. J., J. M. O'Connor and J. A. Hernandez. 1982. PCB dynamics in Hudson River striped bass. 1: Accumulation in early life history stages. Aqua. Toxicol. 2: 187-204.

Clark, K. E. and D. Mackay. 1991. Dietary uptake and biomagnification of four chlorinated hydrocarbons by guppies. Environ. Toxicol. Chem. 10: 1205-1217.

Clayton, Jr. J. R., S. P. Pavlov and N. F. Breitner. 1977. Polychlorinated biphenyls in coastal marine zooplankton bioaccumulation by equilibrium partitioning. Environ. Sci. Tech. 11(7): 676-682.

Cosper, E. M, C. F. Wurster and M. F. Bautista. 1988. PCB-resistant diatoms in the Hudson River estuary. Est. Coast Mar. Sci. 26: 215-226.

Duncan, B T. 1983. The development in the laboratory of resistance to PCB by two marine phytoplankters. M.Sc. Thesis, State University of New York at Stony Brook, USA. 
Duursma, E. K. and M. Marchand. 1974. Aspects of organic marine pollution. Oceanogr. Mar. Biol. Ann. Rev. 12: $315-431$.

Evans, M. S., R. W. Bathelt and C. P. Rice. 1982. PCBs and other toxicants in Mysis relicta. Hydrobiologia 93: 205-215.

Evans, M. S., G. E. Noguchi and C. P. Rice. 1991. The biomagnification of polychlorinated biphenyls, toxaphene, and DDT compounds in a Lake Michigan offshore food web. Arch. Envion. Contam. Toxicol. 20: 87-93.

EPA, 1980. Ambient water quality criteria for polychlorinated biphenyls. U.S. Environmental Protection Agency Rep. 440/5-80-068. $211 \mathrm{pp}$.

Ernst, W. 1984. Pesticides and technical organic chemicals. In: O. Kinne, ed., Marine Ecology. Vol. V, Part 4. John Wiley, New York. pp. 1617-1709.

Fisher, N. S., L. B. Graham, E. J. Carpenter and C. Wurster. 1973. Geographic differences in phytoplankton sensitivity to PCB's. Nature. 241: 548-549.

Mahanty, H. K., B. A. Fineran and P. M. Gresshoff. 1983. Effects of polychlorinated biphenyls (Aroclor 1242) on the ultrastructure of certain planktonic algae. Bot. Gaz. 144: 56-61.

O'Connors, H. B. Jr., C. F. Wurster, C. D. Powers and R. G. Rowland. 1978. Polychlorinated biphenyls may alter marine trophic pathways by reducing phytoplankton size and production. Science. 201: 737-739.

O'Connor, J. M. and J. C. Pizza. 1987. Pharmacokinetic model for the accumulation of PCBs in marine fish. In: J.

M. Capuzzo and D. R. Kester, Oceanic processes in marine pollution volume 1, Robert E. Krieger Publishing Company, Inc., Florida, pp 119-129.

Oliver, B. G. and A. J. Niimi. 1988. Trophodynamic analysis of polychlorinated biphenyl congeners and other chlorinated hydrocarbons in the Lake Ontario Ecosystem. Environ. Sci. Technol. 22: 388-397.

Phillips, D. J. H. 1994. Ecotoxicological impacts of PCBs. Mar. Pollu. Bull. 28(4): 192-193.

Rasmussen, J. B., D. J. Rowan, D. R. S. Lean and J. H. Carey. 1990. Food chain structure in Ontario lakes determines PCB levels in lake trout (Salvelinus namaycush) and other pelagic fish. Can. J. Fish. Aquat. Sci. 47: 2030-2038

Richer G. and R. H. Peters. 1993. Determinants of the short-term dynamics of PCB uptake by plankton. Environ Toxicol. Chem. 12: 207-218.

Rohrer, T. K., J. C. Forney and J. H. Harting. 1982. Organochlorine and heavy metal residues in standard fillets of coho and chinook salmon of the Great Lakes-1980. J. Great Lakes Res. 8: 623-634.

Scura, E. D. and G. H. Theilacker. 1977. Transfer of the chlorinated hydrocarbon PCB in a laboratory marine food chain. Mar. Biol. 40: 317-325.

Skoglund, R. S., K, Stange and D. L. Swackhamer. 1996. A kinetics model for predicting the accumulation of PCBs in phytoplankton. Environ. Sci. Technol. 30: 2113-2120.

Snyder, B. J. 1985. The development of resistance and cross-resistance to chlorinated hydrocarbons by a marine diatom. M. Sc. Thesis, State University of New York at Stony Brook, USA.

Spacie, A. and J. L. Hamelink. 1985. Bioaccumulation. In: G. M. Rand and S. R. Petrocelli, Fundamentals of aquatic toxicology: methods and applications. Hemisphere Publishing Co.,Washington. pp. 495-524.

Swackhamer, D. L. and R. S. Skoglund. 1993. Bioaccumulation of PCBs by algae: Kinetics versus equilibrium Environ. Toxicol. Chem. 12: 831-838.

Thomman, R. V. and J. P. Connolly. 1984. Model of PCB in the Lake Michigan lake trout food chain. Environ Sci. Technol. 18: 65-71

Tanabe, S. 1988. PCB problems in future: foresight from current knowledge. Environ. Pollu. 50: 5-28

Van der Oost, R., H. Heida and A. Opperhuizen. 1988. Polychlorinated biphenyl congeners in sediments, plankton, molluscus, crustaceans, and eel in a freshwater lake: implications of using reference chemicals and indicator organisms in bioaccumulation studies. Arch. Environ. Contam. Toxicol. 17: 721-729

van Sprang, P., P. h. Léger and P. Sorgeloos. 1991. A new test system for the evaluation of toxic levels of lipsoluble products in the aquatic food chain using Artemia and Mysidopsis bahia as experimental animals Aquatic Toxicol. 19:319-328. 